\title{
Volatility Smirk as an Externality of Agency Conflict and Growing Debt
}

\author{
Marcin Jaskowskil
}

Michael McAleer²

1 Econometric Institute, Erasmus School of Economics, Erasmus University Rotterdam,

2 Tinbergen Institute, The Netherlands; Department of Quantitative Finance, National Tsing Hua University, Taiwan; Department of Quantitative Economics, Complutense University of Madrid, Spain. 
Tinbergen Institute is the graduate school and research institute in economics of Erasmus University Rotterdam, the University of Amsterdam and VU University Amsterdam.

More TI discussion papers can be downloaded at http://www.tinbergen.nl

Tinbergen Institute has two locations:

Tinbergen Institute Amsterdam

Gustav Mahlerplein 117

1082 MS Amsterdam

The Netherlands

Tel.: +31(0)205251600

Tinbergen Institute Rotterdam

Burg. Oudlaan 50

3062 PA Rotterdam

The Netherlands

Tel.: +31(0)10 4088900

Fax: $+31(0) 104089031$

Duisenberg school of finance is a collaboration of the Dutch financial sector and universities, with the ambition to support innovative research and offer top quality academic education in core areas of finance.

DSF research papers can be downloaded at: http://www.dsf.nl/

Duisenberg school of finance

Gustav Mahlerplein 117

1082 MS Amsterdam

The Netherlands

Tel.: +31(0)20 5258579 


\title{
Volatility Smirk as an Externality of Agency Conflict and Growing Debt*
}

\author{
Marcin Jaskowski ${ }^{1}$ and Michael McAleer ${ }^{\dagger 1,2,3,4}$ \\ ${ }^{1}$ Econometric Institute, Erasmus School of Economics, \\ Erasmus University Rotterdam \\ ${ }^{2}$ Tinbergen Institute, The Netherlands \\ ${ }^{3}$ Department of Quantitative Finance, National Tsing Hua University, Taiwan \\ ${ }^{4}$ Department of Quantitative Economics, Complutense University of Madrid, Spain
}

Revised: August 2013

\begin{abstract}
Since Black (1976), the source of the stock price volatility smirk has remained a controversy. The volatility smirk is a side effect of agency conflict. An important distinction is that the smirk occurs in the optimum, even after agency conflict has been resolved. The slope of the smirk is found to increase with the severity of the initial agency conflict between management and investors. It is predicted that the higher is the compensation of the manager, the steeper will be the volatility smirk, both for time series and cross sections of companies. These results may help to disentangle the leverage effect from other potential explanations like volatility feedback, the time-varying risk premium, and a down-market effect.
\end{abstract}

Keywords: Volatility Smirk, Asymmetric Volatility Smile, Agency Conflict, Debt Externality, Leverage.

JEL: D81, G12, G13, G32.

*Acknowledgments: The authors wish to thank Dick van Dijk, Eberhard Mayerhofer, Yuliy Sannikov and Wing Wah Tham for helpful comments and suggestions.

${ }^{\dagger}$ For financial support, the second author wishes to acknowledge the Australian Research Council, National Science Council, Taiwan, and the Japan Society for the Promotion of Science. 


\section{InTRODUCTION}

Bernanke and Gertler (1989) showed that financial conditions of firms and households may constitute an important determinant of economic fluctuations. In particular, they showed that financial conditions of borrowers in combination with agency problems have the power to accelerate macroeconomic fluctuations. Moreover, the aggregate effects may be asymmetric because the agency problem binds only on the "down" side. The results of this paper provide a micro parallel to Bernanke and Gertler (1989). We find that agency problems and volatility are intimately linked, and use this relationship to shed light on the phenomenon of asymmetric volatility smiles.

The asymmetric relation between returns and volatility, known as the "volatility smirk" or "asymmetric volatility smile", was first identified by Black (1976) and tested by Christie (1982) and Nelson (1991). In this paper, we identify a link between the stochastic volatility smirk and agency conflicts. The actions of improperly supervised management might lead to higher risk in several ways. For instance, a manager of a company that is close to bankruptcy might decide to invest in a high risk project in an attempt to save the company and their position. Consequently, there would be an endogenous relationship between falling stock prices and an increase in the risk of bankruptcy. These and similar examples would seem to be a trivial manifestation of the agency conflict that leads to a volatility smirk.

In this paper, the mechanism leading to stochastic volatility is different. We show that the stochastic volatility smirk is a fundamental property of the optimal contract that solves the agency conflict. In this model the manager does not take any unnecessary risks when the company approaches the default boundary. On the contrary, the optimal contract is incentive compatible and ensures that the manager does not misbehave. The stochastic volatility smirk is shown to be a side effect of the optimal contract solving the agency problem. In this sense, the volatility smirk is shown to be a generic feature of the stock price process of publicly traded companies. Importantly, in contrast to Bernanke and Gertler (1989), we keep the level of agency costs constant, but we allow time variation in leverage. Still, the result is in a sense similar, stochastic volatility is increasing. In other words, an exogenous shock decreasing the cash flows of firms across the whole economy, will lead to more pronounced fluctuations even if the agency costs are held constant.

We use the setting of DeMarzo and Sannikov (2006) (hereafter DS). It is shown that a continuous time principal agent model can generate stochastic volatility of stock prices. Stock price volatility turns out to be negatively related with the cash flow process and with the returns on stock prices, such that the lower is the stock price, the higher is its volatility. In the model, when the stock price declines, the draw on the credit line also increases and the company's leverage increases. 
Consequently, we obtain a typical asymmetric volatility smirk, which is known as the "leverage" effect.

Second, we show that the principal agent framework can provide new insights into the nature of stochastic volatility. It is shown that the severity of the agency conflict has a critical impact on the magnitude of the volatility smirk. This holds both for the time series and cross-sections of companies. That is, for a given leverage ratio and stock prices a company with great agency conflict initially will experience a higher magnitude of stock price volatility. On the other hand, in time series the stock price volatility moves within an interval defined by the cash-flow volatility and a function that is proportional to the agency conflict severity. In other words, the severity of the agency conflict has an effect on the steepness of the volatility smirk slope. For companies with severe initial agency conflict, stochastic volatility may also explode to infinity when the stock price falls to zero.

Finally, we suggest a new theoretical argument that may help in distinguishing different sources of the volatility smirk. The leverage effect and time-varying risk premium are usually suggested as two main explanations, but they are incompatible with each other. The problem lies in the fact that they assume different directions of causality, so that it is difficult to reject any of the explanations based on these two possibilities.

We propose an avenue that may circumvent the problem of causality. Essentially, we advocate a theoretically-motivated instrumental variable which is correlated with the volatility smirk, but should be independent of the time-varying risk premium. The novelty of the approach comes from linking stock price volatility to the severity of the initial agency conflict between investors and the management of the company. Using the results of the paper, we redefine severity of an agency conflict in terms of a particular choice of a company's capital structure. Specifically, the management compensation is shown to be proportional to the initial severity of the agency conflict.

However, it should be stressed that we consider only companies where the agency conflict has been solved. This means that the manager of the company acts in the best interests of equity shareholders and debt holders. The outcome hinges on the assumption that successful companies are able to finance their projects precisely because they are able to mitigate their agency conflicts. The agency conflict is endogenously solved by an optimal contract in which management has no incentive to misbehave. The optimal contract is implemented through market securities rather than through other corporate governance solutions. In other words, all the information about the agency conflict is reflected in the capital structure of the company and in the market prices of the company's securities. Moreover, management compensation is endogenous and cannot be reduced without the risk of violating incentive compatibility constraints. 
The problem of identifying companies where the agency conflict has been solved may be delicate. However, it should be possible to find companies that meet a few simple conditions. The sample would need to consist of companies in which the supervisory board did not take any significant actions against the management. Additionally, major changes in cash flows should be exogenous to the actions of the management. Essentially, these are companies for which major changes in cash flows are not related to poor governance issues or management misbehavior.

If the optimal contract is implemented, we can find an empirical proxy for the initial severity of the agency conflict. In this model, volatility risk is not priced and there are no additional shocks to volatility, but there is one Brownian motion process of the company's cash flow. It would be difficult to imagine any direct connection between the initial severity of the agency conflict and any sort of CAPM-type of volatility feedback, as described in Bekaert and $\mathrm{Wu}(2000)$. The severity of an agency conflict would seem to be an idiosyncratic factor. Therefore, we feel safe in postulating that the severity of agency conflict is independent of the time-varying risk premium.

As it is found that initial agency conflicts may be strongly related to the stochastic volatility smirk, we conjecture that we have also found an appropriate candidate for the instrumental variable. This might differentiate the leverage effect from other potential explanations, such as volatility feedback, time-varying risk premium, or a down-market effect.

We build on a continuous time agency model from DS. Section 2 briefly reviews the literature on the source of asymmetric volatility and on dynamic contracting models. Section 3 provides a short description of the DS model. The main results of the paper are given in Section 4. Section 5 concludes the paper.

\section{Literature Review}

This paper has links to several different and well established strands of literature. First, we have a predominantly empirical literature dealing with stochastic volatility and the asymmetric relation between stock price volatility and stock returns. Second, we have a vast and predominantly theoretical literature dealing with contract theory. In this paper we show that certain new developments from contract theory may also be useful in resolving some problems in the stochastic volatility literature. Third, the macroeconomics literature has recognized the importance of agency conflicts and debt as amplifying mechanisms for business fluctuations.

It appears that the stochastic volatility literature has so far been unable to reach a consensus as to the source of the volatility smirk. The direction of causality between volatility and returns has been especially elusive. The reason for this is as follows. The leverage effect assumes that a fall in 
the value of the stock increases financial leverage, which makes the stock riskier and leads to higher volatility. Explanations related to the risk premium begin with an assumption that volatility risk is priced. Thus, an anticipated increase in volatility may command an increase in the required return on equity, which results in a concurrent fall in the stock price.

Accordingly, the leverage hypothesis contends that returns shocks lead to changes in volatility, while the time-varying risk premium hypothesis assumes that return shocks are the result of changes in volatility. Clearly, the leverage effect and the time-varying risk premium explanation exclude one another.

For example, early papers such as Black (1976), Christie (1982) and Nelson (1991) attribute the volatility smirk to the leverage effect. Later, Bekaert and $\mathrm{Wu}(2000)$ argue that the leverage effect is not sufficient as an explanation. They argue that a volatility feedback mechanism provides a better explanation for asymmetric volatility. Moreover, Figlewski and Wang (2000) documents a strong relationship between falling prices and increasing stock volatility. However, they find many anomalies in this relationship, which leads to the conclusion that it would be more appropriate to call it "a down market effect". Finally, using a large panel of merged CRSP and COMPUSTAT stock data, Ericsson, Huang, and Mazzotta (2007) find additional evidence in support of the leverage effect hypothesis.

Our results can shed some light on cases where it may be difficult to distinguish between the leverage effect and the time-varying risk premium. We provide a link between the primarily empirical literature on the volatility smirk and the growing literature on agency and dynamic contracting.

Several papers have enriched the problem of optimal incentive provision in a dynamic setting using the mathematical tools of optimal control of diffusion processes. In general, the methods used in this paper were developed in Sannikov (2007) and DS. More specifically, we base our results on the model from DS that proposed a continuous time version of the DeMarzo and Fishman (2007) model. Although the DS model generates the same results as the DeMarzo and Fishman model, it has been an important advance as it significantly improves the tractability and clarity of the results. The advantages of the DS and Sannikov (2007) methodology have been widely recognized, especially in corporate finance, which has led to a stream of new papers. Examples of these papers include Biais, Mariotti, Plantin, and Rochet (2007), Biais, Mariotti, Rochet, and Villeneuve (2010), Brunnermeier and Sannikov (2010), DeMarzo, Fishman, He, and Wang (2012), He (2009), He and Krishnamurthy (2012), Hoffmann and Pfeil (2010) and Piskorski and Tchistyi (2010), Piskorski and Westerfield (2011), among others.

An important branch of macroeconomic models is based on the "costly state verification" notion 
of Townsend (1979). The seminal example here is Bernanke and Gertler (1989), who modified the real business cycle model to account for agency problems. The simple consequence of adding agency problems was to make the Modigliani-Miller theorem inapplicable. Pintus (2011) shows that increasing debt also leads to a higher volatility of macroeconomic fluctuations, as in this paper. At the micro level we show how an increase in overall debt can lead to higher volatility.

\section{THE MODEL}

\subsection{Optimal Contract}

This is an agency model of long term financial contracting, in which a risk-neutral agent seeks funding from a risk-neutral investor, and where funding is used to finance investment in assets. The assets will generate risky cash flow with mean $\mu$ and volatility $\sigma$ :

$$
d Y_{t}=\mu d t+\sigma d Z_{t}
$$

where $Z_{t}$ is a standard Wiener process. The agency problem arises from the fact that the agent can privately observe cash flows $\left\{Y_{t}, t>0\right\}$, but the principal does not. The agent reports cash flows

$\left\{\hat{Y}_{t}, t>0\right\}$ to the principal, but may misreport and divert for their own private consumption. The agent can receive at most a fraction, $\lambda$, from diverted cash flows, where $\lambda \in[0,1]$, so that $1-\lambda$ is the dead-weight cost of "money laundering". If $\lambda=0$, then diversion does not bring any profits and the agency problem disappears.

The principal receives only the reported cash flow from the agent. Based on the reports and according to the contract, the principal transfers a payoff, $d I_{t}$, to the agent, where the payoff process is non-decreasing. The agent's flow of income consists of what is diverted plus the payoff, $d I_{t}$. The only way that the principal can induce the agent to report any positive cash flows is by the threat of terminating the business. Therefore, the contract must specify the time, $\tau$, when the investor terminates cooperation with the agent.

Upon termination of the contract, the agent receives a reservation utility, $R$, and the investors receive the liquidation value, $L$. The risk neutral agent is assumed to have subjective time preference rate, $\gamma$. The agent's total payoff from the contract at time 0 is given by:

$$
W_{0}=E\left[\int_{0}^{\tau} e^{-\gamma t} d C_{t}+e^{-\gamma \tau} R\right]
$$

Investors are also assumed to be risk neutral. They have unlimited capital and discount received 
cash flows at the rate, $r$, such that $r<\gamma$. The principal's total payoff at time 0 is equal to:

$$
b\left(W_{0}\right)=E\left[\int_{0}^{\tau} e^{-r t}\left(d \widehat{Y}_{t}-d I_{t}\right) d t+e^{-r \tau} L\right] .
$$

Before time zero, the principal specifies a contract, $(\tau, I)$, consisting of termination time, $\tau$, and payments to the agent, $\left\{I_{t}, 0 \leq t \leq \tau\right\}$, based on the reports, $\widehat{Y}_{t}$. The agent chooses a strategy, $(C, \widehat{Y})$, as a response to the contract, $(\tau, I)$.

We present an informal argument for the derivation of the optimal contract. The principal's values function, $b(W)$, is the highest transfer to the principal that can be obtained from a contract that delivers an amount, $W$, to the agent. The principal wants to ensure that the marginal cost of compensating the agent in the future does not exceed the cost of an immediate transfer, namely $b_{W}(W) \geq-1$. Given this constraint, we define $W^{1}$ as the lowest value such that $b_{W}(W)=-1$. This constraint, in turn, defines the optimal cash transfers to the agent:

$$
d I=\max \left(W-W^{1}, 0\right) .
$$

These cash transfers and the default boundary keep the agent's continuation value constantly within the interval between $R$ and $W^{1}$. The agent must receive at least a fraction of $\lambda$ of the promised value for each reported dollar so that there is no incentive to misbehave. In this case, the agent's expected payoff consists of transfers from the principal and termination utility:

$$
W_{t}=E_{t}\left[\int_{t}^{\tau} e^{-\gamma(s-t)} d I_{s}+e^{-\gamma(\tau-t)} R\right]
$$

which implies that the agent's continuation value evolves according to:

$$
d W_{t}=\gamma W_{t} d t-d I_{t}+\lambda \sigma d Z_{t}
$$

Using Ito's Lemma and (3), the principal's expected cash flow will follow according to:

$$
E[d Y+d b(W)]=\left(\mu+\gamma W b_{W}(W)+\frac{1}{2} \lambda^{2} \sigma^{2} b_{W W}(W)\right) d t
$$

We know that the principal requires an instantaneous total return equal to the discount rate, $r$. From the Hamilton-Jacobi-Bellman equation, the principal's value function solves the following 
second-order differential equation:

$$
r b(W)=\mu+\gamma W b_{W}(W)+\frac{1}{2} \lambda^{2} \sigma^{2} b_{W W}(W)
$$

with three boundary conditions.

The first boundary condition is from the agent's minimum compensation, $b(R)=L$. The second condition is the smooth pasting condition, $b_{W}(W)=-1$ for $W \geq W^{1}$. Finally, the third condition is the so-called "super contact" condition, which requires that the second derivatives match at the boundary, $b_{W W}(W)=0$ for $W \geq W^{1}$. In order to better understand the last two conditions, we observe that, for $W \geq W^{1}$, we have $r b\left(W^{1}\right)+\gamma W^{1}=\mu$. The interpretation is as follows. The principal can induce truthful cash flow reporting using only two tools, namely the threat of project termination and the postponement of cash payments until $W^{1}$ occurs. Thus, these two boundary conditions define the location of the point, $W^{1}$, when it is most beneficial for the principal to start paying cash to the agent.

The following proposition summarizes the above informal arguments.

Proposition 3.1. A contract that maximizes the principal's profit and delivers to the agent value $W_{0} \in\left[R, W^{1}\right]$ takes the following form: $W_{t}$ evolves as (3). When $W_{t} \in\left[R, W^{1}\right], d I_{t}=0$. When $W_{t}=W^{1}$, payments $d I_{t}$ cause $W_{t}$ to reflect at $W^{1}$. If $W_{0}>W^{1}$, an immediate payment $W_{0}-W^{1}$ is made. The contract is terminated at time, $\tau$, when $W_{t}$ hits $R$. The principal's expected payoff is given by $b\left(W_{t}\right)$ which, at any point on the interval $\left[R, W^{1}\right]$, satisfies (4) and $b_{W}(W)=-1$ for $W>W^{1}$, with boundary conditions $b(R)=L$ and $r b\left(W^{1}\right)=\mu-\gamma W^{1}$.

\subsection{Capital Structure Implementation}

The optimal contract is implemented with three standard securities, namely equity, long term debt and credit line. Equity holders receive dividend payments made by the firm. Dividends are paid from the firm's available cash or credit, and are at the discretion of the agent. Long term debt is a consol bond that pays continuous coupons at the rate, $x$. The coupon rate is $r$, and the face value of debt is $D=x / r$. A revolving credit line provides the firm with available credit up to $C^{L}$. Balances on the credit line are charged a fixed interest rate, $r^{c}$. If the balance on the credit line exceeds $C^{L}$, the firm defaults.

The optimal contract is implemented with a capital structure in which the agent holds equity for a fraction, $\lambda$, of the firm and the credit line has interest rate, $r^{c}=\gamma$. It is incentive compatible for the agent to refrain from stealing, and to use the project cash flows to pay the debt coupons and credit line before issuing dividends. After the credit line is fully repaid, all excess cash flows 
are issued as dividends. Under this capital structure, the agent's expected future payoff, $W_{t}$, is determined by the current draw, $M_{t}$, on the credit line:

$$
W_{t}=W^{1}-\lambda M_{t}
$$

\subsection{Security Market VAlues}

The market value of long term debt, credit line and outside equity is conditional on the draw on the credit line or, equivalently, on the agent's continuation value, $W_{t}$. This occurs because the larger is the draw on the credit line, the higher is the probability of default. The value of equity per share ${ }^{1}$ is equal to:

$$
\begin{aligned}
V_{E}(W) & =E\left[\int_{0}^{\tau} e^{-r t} d D i v_{t} \mid W\right] \\
& =E\left[\int_{0}^{\tau} e^{-r t} \frac{1}{\lambda} d I_{t} \mid W\right]
\end{aligned}
$$

where $d$ Div $=\frac{1}{\lambda} d I$ represents the value of dividends paid out both to the outside equity holders and to the manager.

\section{Volatility Smirk for Time Series And Cross-Sections of Companies}

\subsection{Volatility SMiRK}

At time 0 , if debt is risky, the value of equity is equal to (6). There might also be interest in the evolution of the stock price, that is, how it behaves at time $t>0$. This is straightforward as we just need to condition on $\mathcal{F}_{t}^{Z}$, and integrate from $t$ to $\tau$ rather than from 0 to $\tau$. Define a new function:

$$
S\left(W_{t}\right)=E\left[\int_{t}^{\tau} e^{-r(s-t)} \frac{1}{\lambda} d I_{s} \mid \mathcal{F}_{t}^{Z}, W=W_{t}\right]
$$

We can use $S(W)$ to investigate the properties of the stock price volatility in the DS model, after describing the function $F$. The following lemma is a direct generalization of Lemma D from DS.

\footnotetext{
${ }^{1}$ It is assumed that long term debt is risky such that, in the case of default, equity holders do not receive any termination payoff, $L_{E}=0$.
} 


\section{JAskowski, McAleer}

Lemma 4.1. Suppose $W_{t}$ evolves as in (3) in the interval $\left[R, W^{1}\right]$ until time $\tau$, when $W_{t}$ hits $R$ and bankruptcy occurs. $I_{t}$ is a non-decreasing process that reflects $W_{t}$ at $W^{1}$. Let $F=F\left(W_{t}\right)$ be a $C^{2}$ function with boundary conditions $F(\tau, R)=L$ and $\frac{\partial}{\partial W} F\left(W^{1}\right)=-k$. Then the following two equations are equivalent:

(i) Function F solves

$$
r F\left(W_{t}\right)=f\left(W_{t}\right)+\gamma W \frac{\partial}{\partial W} F\left(t, W_{t}\right)+\frac{1}{2} \lambda^{2} \sigma^{2} \frac{\partial^{2}}{\partial W^{2}} F\left(W_{t}\right)
$$

(ii) F satisfies

$$
F\left(W_{t}\right)=E\left[\int_{t}^{\tau} e^{-r(s-t)} f\left(W_{t}\right) d t-k \int_{t}^{\tau} e^{-r(s-t)} d I_{s}+e^{-r(\tau-t)} L \mid \mathcal{F}_{t}^{Z}, W=W_{t}\right]
$$

Proof. See Appendix A.

The following proposition states that an optimal contract between the investors and the entrepreneur may induce stochastic volatility in stock prices and a volatility smirk.

Proposition 4.2. When debt is risky, the volatility, $\sigma_{E}$, of equity value, $S\left(W_{t}\right)$, is stochastic for all $W_{t}<W^{1}$. Stock price volatility, $\sigma_{E}$, increases with the amount drawn on the credit line, $M_{t}$. For all values $W \geq W^{1}$, the volatility of equity is flat. Therefore, stock price volatility, $\sigma_{E}$, in this model exhibits the property called a volatility smirk.

Proof. The stock price function, $S(W)$, is a special case of $F\left(W_{t}\right)$, from Lemma 4.1. We observe that, in this case, $k=-\frac{1}{\lambda}$ and $f\left(W_{t}\right)=0$. Using these facts and Ito's Lemma, we can derive the dynamics of (7):

$d S\left(W_{t}\right)=\left\{\gamma W_{t} S_{W}\left(W_{t}\right)+\frac{1}{2} \lambda^{2} \sigma S_{W W}\left(W_{t}\right)-r S\left(W_{t}\right)\right\} d t+\left(\frac{1}{\lambda}+S_{W}\left(W_{t}\right)\right) d I_{t}+\underbrace{\sigma \lambda S_{W}\left(W_{t}\right)}_{=\sigma_{E}} d Z_{t}$.

The Ito dynamics of $S$ give the stock price volatility:

$$
\sigma_{E}\left(t, W_{t}\right)=\sigma \lambda S_{W}\left(W_{t}\right)
$$

We need to describe some of the properties of the function, $S$. From stochastic representation, we can show that $S$ is increasing in $W$. Lemma A.1 from Appendix A shows that function $S$ is 
concave in $W$. Thus, for every $t$, we have:

$$
\begin{aligned}
S_{W}\left(W_{t}\right) & >0 \\
S_{W W}\left(W_{t}\right) & <0 .
\end{aligned}
$$

Additionally, from (5), it can be shown that:

$$
\frac{\partial}{\partial M} \sigma_{E}(t, W)=\frac{\partial}{\partial M}\left(\sigma \lambda S_{W}\left(W_{t}\right)\right)=\sigma \lambda \frac{\partial}{\partial W} S_{W}\left(W_{t}\right) \underbrace{\frac{d W}{d M}}_{=-\lambda}=-\sigma \lambda^{2} \underbrace{S_{W W}\left(W_{t}\right)}_{<0}>0 .
$$

Summarizing, the volatility of the stock price is increasing in $M$ :

$$
\frac{\partial}{\partial M} \sigma_{E}>0
$$

that is, increasing in the draw on the credit line. The agent has to draw on the credit line when the cash flows are not sufficient to repay the coupon on the long term debt. This also increases a firm's leverage and credit risk. Altogether, it means that, when the cash flows fall, stock price volatility increases. This leads to an asymmetric stochastic volatility smirk, with greater slope in the direction of negative cash flows.

An asymmetric stochastic volatility smirk is defined in terms of the derivative with respect to $M$, that is, a draw on the credit line. We could also take the derivative of $\sigma_{E}$ with respect to the continuation value, $W$, which would only change the sign of the relation:

$$
\frac{\partial}{\partial W} \sigma_{E}<0
$$

This arises because the continuation value of the agent, $W$, and the draw on the credit line, $M$, always move in opposite directions. This is intuitive, as the agent has to draw on the credit line only if cash flows are not sufficient to cover the costs of long term debt. The continuation value, $W$, will also fall. In other words, the higher is the continuation value of the agent, the lower will be the stock price volatility for the principal.

\subsection{Volatility Smirk for Time Series of Companies}

It is known that the firm's capital structure is such that the payout policy is incentive compatible for the manager. Thus, it is optimal for the manager to pay out dividends only when the credit line is fully paid down. What about outside equity holders? Would they prefer a different strategic 
default policy, such as an alternative payout policy? Could the firm raise new equity capital to delay default?

For each dollar paid out in dividends, the outside equity holders receive only $1-\lambda$. Using the first derivative of $S\left(W_{t}\right)$, we might estimate the impact of drawing one dollar more on the value of equity, $S\left(W_{t}\right)$. First, we note that the increased draw on the credit line changes the value of outside equity holders by $(1-\lambda) \frac{\partial}{\partial M} S\left(W_{t}\right)$. Thus, equity holders will not benefit from paying themselves additional dividends at the expense of a higher draw on credit line, unless:

$$
-(1-\lambda) \frac{\partial}{\partial M} S\left(W_{t}\right) \times d D i v_{t} \geq(1-\lambda) d D i v_{t}
$$

or equivalently:

$$
\frac{\partial}{\partial M} S\left(W_{t}\right) \leq-1
$$

When debt is risky, $L<D+C^{L}$, the above relationship holds with equality for $M_{t}=0$. This means that equity holders have no incentive to alter the firm's payout policy.

On the other hand, the company might decide to pay down some of the draw on the credit line by raising new capital through an equity issue. All such capital must come from outside shareholders, who will not buy any new shares unless:

$$
\text { dollar } \geq-(1-\lambda) \frac{\partial}{\partial M} S\left(W_{t}\right) \times \text { dollar }
$$

That is, one dollar that is used to pay down the draw on the credit line must amount to more than a one dollar increase in the value of the equity $\left.\right|^{2}$. Combining the two inequalities gives:

$$
-\frac{1}{1-\lambda} \leq \frac{\partial}{\partial M} S\left(W_{t}\right) \leq-1
$$

Surprisingly, we may also find that the two inequalities above place constraints on the value of stochastic volatility. This is summarized in the next proposition.

Proposition 4.3. When debt is risky, the magnitude of stock price volatility, $\sigma_{E}$, belongs in the interval:

$$
\sigma_{E} \in\left[\sigma, \frac{1}{1-\lambda} \sigma\right] .
$$

Proof. Here we use the previously stated inequality 10 . From the fact that $W_{t}$ is a linear function of $M_{t}, W_{t}=W^{1}-\lambda M_{t}$, we observe that:

\footnotetext{
${ }^{2}$ This reasoning constitutes a proof of Proposition 6 from DeMarzo and Sannikov (2006) about the firm's optimal payout policy.
} 


$$
\begin{aligned}
\frac{\partial}{\partial M} S(W) & =\frac{\partial}{\partial M} S(W) \\
& =S(W) \underbrace{\frac{d W}{d M}}_{=-\lambda} \\
& =-\lambda S_{W}(W) .
\end{aligned}
$$

Then we substitute this formula into $(10)$ and multiply by $\sigma$ to obtain:

$$
-\frac{1}{1-\lambda} \sigma \leq \underbrace{-\lambda S_{W}(W) \sigma}_{=-\sigma_{E}} \leq-\sigma,
$$

which yields the the result:

$$
\sigma \leq \sigma_{E} \leq \frac{1}{1-\lambda} \sigma
$$

Empirically, $\lambda$ corresponds to the amount of shares held by the management of the company. If $\lambda$ is close to 0 , the agency problem also disappears and we observe neither stochastic volatility of stock prices nor a volatility smirk. However, if $\lambda$ tends to 1 , then:

$$
\lim _{\lambda \rightarrow 1} \frac{1}{1-\lambda} \sigma=\infty
$$

Obviously, according to this model, stock volatility, $\sigma_{E}$, would also explode to infinity.

\subsection{Volatility Smirk for Cross-Sections of Companies}

Empirically, it is difficult to disentangle the leverage effect from the time-varying risk premium. However, we can suggest a novel and testable prediction that may assist in interpreting uncertainty and the leverage effect, not in the time series of stock returns but in their cross-sections. Specifically, we show that the magnitude of the volatility smirk increases with the parameter, $\lambda$.

Proposition 4.4. For a fixed continuation value, $W$ (or $M)$, stock price volatility, $\sigma_{E}$, increases with $\lambda$ for $W_{t}<W^{1}$. For $W_{t} \geq W^{1}$, we have $\sigma_{E}=\sigma$.

Proof. We need to show that, for a given value of $W, \sigma_{E}$ is actually increasing in $\lambda$ in the crosssection. For $W_{t} \geq W^{1}$, we have $S_{W}\left(W_{t}\right)=\frac{1}{\lambda}$, so $\sigma_{E}=\lambda \sigma \frac{1}{\lambda}=\sigma$. Now, for $W_{t}<W^{1}$, we have 
$S_{W W}\left(W_{t}\right)<0$. Therefore, on the left-hand side of $W^{1}$, we will always have $S_{W}\left(W_{t}\right)>\frac{1}{\lambda}$, and $S_{W}$ is decreasing in $W$, which proves the proposition as

$$
\sigma_{E}(t, W)=\sigma \underbrace{\lambda \underbrace{S_{W}\left(W_{t}\right)}_{>\frac{1}{\lambda}}}_{>1}
$$

for every $W_{t}$. Therefore, $\sigma_{E}$ must increase together with $\lambda$ for every given $W_{t}$. In other words, for $W<W^{1}$, we have

$$
\frac{\partial}{\partial \lambda} \sigma_{E}>0
$$

This observation provides an empirically testable fact. DeMarzo and Sannikov (2006) showed that $\lambda$ is an important parameter for the implementation of the optimal contract, as it is a fraction of the cash flows that the manager can divert. For obvious reasons, it is difficult to observe stolen money. Fortunately, in this model the manager does not need to steal. The optimal capital structure guarantees that the manager receives the fraction, $\lambda$, of cash flows in the form of dividends. That is, in the optimum, $\lambda$ defines the number of shares that the manager holds. Therefore, Proposition 4.4 suggests we should observe that the stock price of companies in which management holds a larger stake exhibits a more pronounced volatility smirk.

Another advantage of this measure is that it should assist in clarifying different interpretations of the asymmetric volatility. The parameter, $\lambda$, as a measure is clearly independent of timevarying risk, volatility feedback or a "down market effect", as all of these measures refer to time series properties. Consequently, we might use $\lambda$ as an instrumental variable to disentangle the influence of the leverage effect on asymmetric volatility from other effects.

\section{Conclusions}

The main contributions of this paper are insights into the potential determinants of the asymmetric relationship between volatility and stock returns. We showed that the dynamic principal agent model can show a pattern of stock price volatility behavior that is usually attributed to the human component. Under a standard Brownian motion, the prices and behavior of securities are symmetric because the normal probability distribution of the Wiener process favors neither positive nor negative fluctuations. In this model, we can observe a volatility smirk, with an asymmetric grin 
in the direction of a higher draw on the credit line and negative cumulative cash flows. However, it is not due to investors becoming increasingly nervous, but rather as a side effect of the contractual solution to the principal-agent problem.

We also showed that the magnitude of the volatility smirk increased with the severity of the agency conflict in the firm, both in the time series and in cross-sections of companies. In the context of this model, the severity of agency conflict can be observed indirectly as it is proportional to the number of the company's shares held by the manager. This led to the proposal of a new instrumental variable that should help to disentangle the leverage effect from other mechanisms influencing asymmetric volatility. In particular, we hypothesized that the number of stock shares held by the manager would be positively correlated with the magnitude of the volatility smirk. Therefore, a number of stock shares held by the manager, as a proxy for the severity of the agency conflict, may serve as an instrumental variable in tests for the source of asymmetric volatility in stock returns. 


\section{A Appendix}

Lemma A.1. Function $S(W)$ for all $t$ is concave.

Proof. We have $S_{W}(W)>0$, which is clear from (2) and (7). Suppose that $S$ were not concave somewhere on $\left[R, W^{1}\right]$, and let $V=\inf \left\{S_{W W}(W)>0\right\}$. Then $V>R$ and $S_{W W}(V)=0$, by continuity of $S_{W W}$. But then

$$
\frac{1}{2} \lambda^{2} \sigma^{2} S_{W W W}(V)=(r-\gamma) S_{W}(V)-\gamma V S_{W W}(V)=(r-\gamma) S_{W}(V)<0,
$$

so $S_{W W}(V+\varepsilon)<0$ for all sufficiently small $\varepsilon>0$, which is a contradiction.

Next, we prove Lemma 4.1, which is an "if and only if" statement and needs to be done in two steps.

Proof of Lemma 4.1. $\Rightarrow$ Suppose that F solves (8), then we show that it satisfies (9). Define

$$
\widetilde{H}_{u}=\int_{t}^{u} e^{-r(s-t)} f\left(W_{u}\right) d t-k \int_{t}^{u} e^{-r(s-t)} d I_{s}+e^{-r(u-t)} F\left(W_{u}\right) .
$$

Using Ito's Lemma,

$$
\begin{aligned}
e^{r(u-t)} d \widetilde{H}_{u}= & -k d I_{u}-r F\left(W_{u}\right) d u+f\left(W_{u}\right) d u+\gamma W \frac{\partial}{\partial W} F\left(W_{u}\right) d u-\frac{\partial}{\partial W} F\left(W_{u}\right) d I_{u}+ \\
& +\lambda \sigma \frac{\partial}{\partial W} F\left(W_{u}\right) d Z_{u}+\frac{1}{2} \lambda^{2} \sigma^{2} \frac{\partial^{2}}{\partial W^{2}} F\left(W_{u}\right) d u
\end{aligned}
$$

which, after rearranging, gives

$$
\begin{aligned}
e^{r(u-t)} d \widetilde{H}_{u}= & \underbrace{\left\{f\left(W_{u}\right)+\gamma W \frac{\partial}{\partial W} F\left(W_{u}\right)+\frac{1}{2} \lambda^{2} \sigma^{2} \frac{\partial^{2}}{\partial W^{2}} F\left(W_{u}\right)-r F\left(W_{u}\right)\right\}}_{=0} d u+ \\
& +\left(-k+\frac{\partial}{\partial W} F\left(W_{u}\right)\right) d I_{u}+\lambda \sigma \frac{\partial}{\partial W} F\left(W_{u}\right) d Z_{u} .
\end{aligned}
$$

This equation leads to

$$
e^{r(u-t)} d \widetilde{H}_{u}=-\left(k-\frac{\partial}{\partial W} F\left(W_{u}\right)\right) d I_{u}+\lambda \sigma \frac{\partial}{\partial W} F\left(W_{u}\right) d Z_{u} .
$$

We observe that either $W_{u}<W^{1}$ and $d I_{u}=0$, or $W_{u} \geq W^{1}$, and then $\frac{\partial}{\partial W} F\left(W_{u}\right)=k$, so $\widetilde{H}_{u}$ is a 
martingale, which implies:

$$
F\left(t, W_{t}\right)=\widetilde{H}_{t}=E\left[\widetilde{H}_{\tau}\right]=E\left[\int_{t}^{\tau} e^{-r(s-t)} f\left(W_{s}\right) d s+\int_{t}^{\tau} e^{-r(s-t)} d I_{s}+e^{-r(\tau-t)} L \mid \mathcal{F}_{t}^{Z}\right]
$$

$\Leftarrow \mathrm{It}$ is sufficient to show that $\widetilde{H}_{u}$ is a martingale if $F\left(W_{t}\right)$ solves $E\left[\int_{t}^{\tau} e^{-r(s-t)} d I_{s} \mid \mathcal{F}_{t}^{Z}\right]$. Let $\widetilde{H}_{u}$ be

$$
\widetilde{H}_{u}=\int_{t}^{u} e^{-r(s-t)} d I_{s}+e^{-r(u-t)} F\left(W_{u}\right)
$$

We can show that $\widetilde{H}_{u}$ is a martingale using the law of iterated expectations. Assume that $t<u<$ $t^{\prime}<\tau$, and we need to show that $E\left[E\left[\widetilde{H} \mid \mathcal{F}_{t^{\prime}}^{Z}\right] \mid \mathcal{F}_{u}^{Z}\right]=E\left[\widetilde{H} \mid \mathcal{F}_{u}^{Z}\right]$. Define:

$$
\begin{aligned}
\widetilde{H}_{t^{\prime}} & =\int_{t}^{t^{\prime}} e^{-r s} d I_{s}+e^{-r t^{\prime}} F\left(W_{t^{\prime}}\right)=E\left[\int_{t}^{t^{\prime}} e^{-r s} d I_{s}+e^{-r t^{\prime}} F\left(W_{t^{\prime}}\right) \mid \mathcal{F}_{t^{\prime}}^{Z}\right]=E\left[\widetilde{H}_{t^{\prime}} \mid \mathcal{F}_{t^{\prime}}^{Z}\right] \\
\widetilde{H}_{u} & =\int_{t}^{u} e^{-r s} d I_{s}+e^{-r u} F\left(W_{u}\right)=E\left[\int_{t}^{u} e^{-r s} d I_{s}+e^{-r u} F\left(W_{u}\right) \mid \mathcal{F}_{u}^{Z}\right]=E\left[\widetilde{H}_{u} \mid \mathcal{F}_{u}^{Z}\right] \\
F\left(t^{\prime}, W_{t^{\prime}}\right) & =E\left[\int_{t^{\prime}}^{\tau} e^{-r\left(s-t^{\prime}\right)} d I_{s} \mid \mathcal{F}_{t^{\prime}}^{Z}\right] \\
F\left(u, W_{u}\right) & =E\left[\int_{u}^{\tau} e^{-r(s-u)} d I_{s} \mid \mathcal{F}_{u}^{Z}\right] .
\end{aligned}
$$

With these, we can show that the law of iterated expectations holds:

$$
\begin{aligned}
& E\left[E\left[\widetilde{H}_{t^{\prime}} \mid \mathcal{F}_{t^{\prime}}^{Z}\right] \mid \mathcal{F}_{u}^{Z}\right] \\
&=E\left[\int_{t}^{t^{\prime}} e^{-r s} d I_{s}+e^{-r t^{\prime}} F\left(W_{t^{\prime}}\right) \mid \mathcal{F}_{u}^{Z}\right] \\
&=E\left[\int_{t}^{u} e^{-r s} d I_{s}+\int_{u}^{t^{\prime}} e^{-r s} d I_{s}+e^{-r t^{\prime}} E\left[\int_{t^{\prime}}^{\tau} e^{-r\left(s-t^{\prime}\right)} d I_{s} \mid \mathcal{F}_{t^{\prime}}^{Z}\right] \mid \mathcal{F}_{u}^{Z}\right] \\
&=E\left[\int_{t}^{u} e^{-r s} d I_{s}+e^{-r t^{\prime}} E\left[\int_{u}^{t^{\prime}} e^{-r s} e^{r t^{\prime}} d I_{s} \mid \mathcal{F}_{u}^{Z}\right]+e^{-r t^{\prime}} E\left[\int_{t^{\prime}}^{\tau} e^{-r\left(s-t^{\prime}\right)} d I_{s} \mid \mathcal{F}_{t^{\prime}}^{Z}\right] \mid \mathcal{F}_{u}^{Z}\right] \\
&=E\left[\int_{t}^{u} e^{-r s} d I_{s}+e^{-r t^{\prime}}\left\{E\left[\int_{u}^{t^{\prime}} e^{-r\left(s-t^{\prime}\right)} d I_{s} \mid \mathcal{F}_{u}^{Z}\right]+E\left[\int_{t^{\prime}}^{\tau} e^{-r\left(s-t^{\prime}\right)} d I_{s} \mid \mathcal{F}_{t^{\prime}}^{Z}\right]\right\} \mid \mathcal{F}_{u}^{Z}\right]
\end{aligned}
$$




\section{JASKOWski, MCALEER}

$$
\begin{aligned}
& =E\left[\int_{t}^{u} e^{-r s} d I_{s}+e^{-r t^{\prime}}\left\{E\left[\int_{u}^{t^{\prime}} e^{-r\left(s-t^{\prime}\right)} d I_{s} \mid \mathcal{F}_{u}^{Z}\right]+E\left[\int_{t^{\prime}}^{\tau} e^{-r\left(s-t^{\prime}\right)} d I_{s} \mid \mathcal{F}_{u}^{Z}\right]\right\} \mid \mathcal{F}_{u}^{Z}\right] \\
& =E\left[\int_{t}^{u} e^{-r s} d I_{s}+e^{-r t^{\prime}} E\left[\int_{u}^{t^{\prime}} e^{-r\left(s-t^{\prime}\right)} d I_{s}+\int_{t^{\prime}}^{\tau} e^{-r\left(s-t^{\prime}\right)} d I_{s} \mid \mathcal{F}_{u}^{Z}\right] \mid \mathcal{F}_{u}^{Z}\right] \\
& =\int_{t}^{u} e^{-r s} d I_{s}+e^{-r t^{\prime}} e^{-r\left(-t^{\prime}+u\right)} E\left[\int_{u}^{\tau} e^{-r(s-u)} d I_{s} \mid \mathcal{F}_{u}^{Z}\right] \\
& =\int_{t}^{u} e^{-r s} d I_{s}+e^{-r u} F\left(W_{u}\right)=\widetilde{H}_{u}=E\left[\widetilde{H}_{u} \mid \mathcal{F}_{u}^{Z}\right]
\end{aligned}
$$

which proves that $\widetilde{H}_{u}$ is a martingale, so its drift must be equal to zero. 


\section{JAskowski, McAleer}

\section{REFERENCES}

Bekaert, G., and G. Wu, 2000, Asymmetric volatility and risk in equity markets, Review of Financial Studies 13, 1-42.

Bernanke, B., and M. Gertler, 1989, Agency costs, net worth, and business fluctuations, American Economic Review 79, 14-31.

Biais, B., T. Mariotti, G. Plantin, and J.-C. Rochet, 2007, Dynamic security design: Convergence to continuous time and asset pricing implications, Review of Economic Studies 74, 345-390.

Biais, B., T. Mariotti, Jean-Charles Rochet, and S. Villeneuve, 2010, Large risks, limited liability, and dynamic moral hazard, Econometrica 78, 73-118.

Black, Fischer, 1976, Studies of stock price volatility changes, Proceedings of the 1976 Meetings of the American Statistical Association, Business and Economical Statistics Section 177-181.

Brunnermeier, M., and Y. Sannikov, 2010, A macroeconomic model with a financial sector, Technical report, Princeton University.

Christie, A.A., 1982, The stochastic behavior of common stock variances: Value, leverage and interest rate effects, Journal of Financial Economics 10, 407-432.

DeMarzo, P., M. Fishman, Z. He, and N. Wang, 2012, Dynamic agency and the q theory of investment, Journal of Finance, forthcoming.

DeMarzo, P.M., and M.J. Fishman, 2007, Optimal long-term financial contracting, Review of Financial Studies 20, 2079-2128.

DeMarzo, P.M., and Y. Sannikov, 2006, Optimal security design and dynamic capital structure in a continuous-time agency model, Journal of Finance 61, 2681-2724.

Ericsson, J., X. Huang, and S. Mazzotta, 2007, Leverage and asymmetrc volatility: the firm level evidence, Technical report, McGill University.

Figlewski, S., and X. Wang, 2000, Is the "leverage effect" a leverage effect?, Technical report, NYU Stern.

He, Z., 2009, Optimal executive compensation when firm size follows geometric brownian motion, Review of Financial Studies 22, 859-892. 


\section{JAskowski, McAleer}

He, Z., and A. Krishnamurthy, 2012, Intermediary asset pricing, American Economic Review, forthcomming.

Hoffmann, F., and S. Pfeil, 2010, Reward for luck in a dynamic agency model, Review of Financial Studies 24, 3329-3345.

Nelson, D.B., 1991, Conditional heteroskedasticity in asset returns: A new approach, Econometrica: Journal of the Econometric Society 347-370.

Pintus, A. P., 2011, International capital flows, debt overhang and volatility, International Journal of Economic Theory 7, 301-315.

Piskorski, T., and A. Tchistyi, 2010, Optimal mortgage design, Review of Financial Studies 24, 3098-3140.

Piskorski, T., and M. Westerfield, 2011, Optimal dynamic contracts with moral hazard and costly monitoring, Marshall School of Business Working Paper No. FBE 36-09.

Sannikov, Y., 2007, Games with imperfectly observable actions in continuous time, Econometrica $75,1285-1329$.

Townsend, M. R., 1979, Optimal contracts and competitive markets with costly state verification, Journal of Economic Theory 21, 265-293. 